\title{
Morphosyntactic Analysis of Inconsistent Formation of English Words, Phrases, and Sentences
}

\author{
Ambalegin \\ Department of English Literature \\ Universitas Putera Batam \\ Batam, Indonesia \\ abhi140475@gmail.com
}

\author{
Melly Siska Suryani \\ Department of English Literature \\ Universitas Putera Batam \\ Batam, Indonesia \\ melsis.suryani@gmail.com
}

\begin{abstract}
Thisqualitative descriptive research wasa morphosyntactic analysis that discussed about morphological and syntactical formation of English words, phrases and sentences. The purpose of this study was to describe the use of rules of words, phrases, and sentences formation in English. It concerned to the inconsistencies in the formation of words, phrases, or sentences that had not been widely described in English textbooks in terms of morphology and syntax. The data were collected used observational method and nonparticipatory technique. Then, the data were analyzed by using referential identity method. The theory used refers to the theories of Yule and Finegan. Furthermore, the results of data analysis are presented descriptively. The result of the research showed the inconsistency of English words, phrases, and sentences formation. The inconsistent formations of English words occurred in regular plural noun formation, irregular plural noun formation, verb formation, suffixingformation, numeral formation, and possession formation. The inconsistent formations of English noun phrases occurred in phrase made of noun and noun, present participle adjective modifying noun, and phrase made of noun and adjective. The inconsistent formations of English sentences occurred in the formation of question tag, if conditional, and question, the use ofsingular and plural verbs in sentences formed by either...or..., modal auxiliary, object pronoun in sentences formed by neither... nor..., verb be and an article in collective noun, the and adjective, and to and present participle in the sentences. This proved that the words, phrases, and sentences whose formations did not follow the common formulation were formed inconsistently.
\end{abstract}

Keywords-formation; inconsistency; morphosyntactic

\section{INTRODUCTION}

This paper is started as theEFL learners get serious difficulties in forming English words, phrases, and sentences. They complain that English is ambiguous and unpredictable. Some EFL learners add suffix es to the word photo into photoes. According to them, the word ended with letter $o$ must be added by suffix es such as potatoes. The EFL learners makemistakeswhile forming the words. The words such as potato, mango, and go as the root word will be added by suffix $e s$ as the last syllable of the words is consonant and the letter $o$. The root word will be added by suffix $s$ if the last syllable ends with vowel and the letter $o$, such as zoos (not zooes), radios (not radioes). There are some inconsistent formations of the word related to the formula above such as pianos (not pianoes), photos (not photoes). Those words show that there are some words follow the rules of word formation and the rest do not, although the wordshave the same last syllable. The formation of words sometimes is inconsistent. There are rules that the EFL learners need to follow such as constructing the words themselves meaningfully and the sentences grammatically correct. The rules which are needed to construct the correct formation makes the English learning complicated. The rules sometimes make the EFL learners reluctant to learn English.

The educator as the person to transfer the knowledge to the EFL learners gave the courses as well as the textbooks given that[1]. As English is not targeted as a habit, makes the EFL learners get problem in learning English[2]. English teachers explain about the word forming morphologically and syntactically, but there are some words formed do not follow the rule morphologically and syntactically. It was known from the interview of EFL learners that they learned the word formation based on the rules on textbooks, such as morpheme types, and affixes. They did not study the word formation which did not follow the rule morphologically and syntactically. The other mistake happened from the students' experience in usingthe article aandan. The EFL learners know the use article aif the noun word is started with consonant, meanwhile the article an is followed by the noun word started with vowel. In fact, it is truly incorrect.

Word as a meaningful smallest language part plays an important role in constructing phrase and sentence. Crystal in Spuy[3] stated that a word is referred to as morphemic, morphosyntactic or grammatical word. It is defined as a grammatical unit whose function is to show how hard words work in the grammar[3].The use of correct words and phrases are hoped to avoid the different point of view of the ideas in the sentences. The changes of word function are formed by combining a few different components of letters, syllables, or words. Speakers or writers must understand the function and meaning of the words or phrases which are presented in the sentences to gain the correctness the use of words or phrases in the sentences. It is important to know deeply about the form of English words, phrases, and sentences inconsistently due to avoid makingmistakes. This paper discusses the morphologically and syntactically inconsistent formation of English words, phrases, and sentences and the involvement of 
lexical categories in inconsistent formation of English words, phrases, and sentences.

\section{SYNTACTIC AND MORPHOLOGICAL ENGLISH}

Speakers of English commonly assume that the normal way of constructing a sentence is to place the subject first, then the verb, and the direct object [4]. Indeed, in English, the sentence Mary saw John, which follows this order, is well formed, while variations like John Mary saw and saw Mary John are not. People deliver the ideas or feeling through language both in spoken and written form. Learning language, people should know about the structure (grammar), meaning and how to pronounce well. Therefore, they need to know about syntax. According to Borsley inHosseinzadeh[5], syntactic theory is concerned the way that words are combined to form a sentence. Then syntax is the study about how the language is built grammatically.

But not all English sentences follow an SVO order. For English speaker sometimes places direct objects in clause initial position as with sewing in sewing I hate, but I will sew that for you[6]. It also appears in written text in Newsweek magazine, September 21 ${ }^{\text {st }}$, 1998, 'In short, a basket case.' Thus, even though, some English constructions do not follow this order, it is said SVO order is basic in English and English is an SVO language [6]\&[4]. Thai, Vietnamese, and Indonesian include SVO languages, Japanese, Burmese, and Hindi are SOV languages, and VSO languages, as are Welsh and some dialects of Arabic [4].

Morphological relationships exist between word forms. As read the above explanation, language, definitely, cannot be separated from words. According to Biber inFlorencia[7], grammatical units are they are meaningful and combine with each other in systematic ways. The hierarchically grammatical units are discourse, sentences, clause, phrase, word, morpheme, and phoneme. It is known that sentence is a set of words expressing a statement, a command, or a question. A sentence consists of one or more clauses. Clause unit has subject, predicator, object, complement, and adverbial. A phrase is a group of two or more words which has head $(\mathrm{H})$ and modifier (M). The phrase is not a clause or sentence but it has a meaning. A word is the smallest unit of a language that has important function to build up the phrases, clauses, and sentences[8]. The important roles of the words can be seen in sentence, clause, phrase, and word.

Morphologically, the word can be formed before it is connected to one another in a phrase, a clause, or a sentence. The words are related to the other words of the same language. Formally, differences among words serve a variety of purposes, from the creation of new lexicon items to the indication of grammatical structure[9].

\section{RESEARCH METHOD}

This research adapted the qualitative-descriptive method. The data were collected by using observational method [10]. The technique used was the nonparticipatory technique [10]. Then, the data were analyzed by using referential identity method [10]. The theory used refers to the theory of Yule and Finegan.

\section{RESULT AND DISCUSSION}

\section{A. The Inconsistence of English Words Formation}

- Regular Plural Noun Formation

Data 1: photos, altos, pianos

Photo, alto, and piano in plural form are showed by adding suffix $s$ but not suffix es (photoes, altoes, pianoes). As the rule shown, suffix es is added to either noun or verb when it is ended with syllable consonant and vowel $o$, meanwhile the noun ended with vowel and vowel (zoos, radios ) is added with suffix $s$ for the plural[4].

Data 2: oxen

$O x$ in plural form is showed by adding suffix en but not suffix es (oxes). As the rule shown, suffix esis added to either noun or verb when it is ended with syllable vowel and consonant $x$ (boxes, foxes, axes) [4].

Data 3: dice

Die in plural form is showed by adding neither suffix es nor suffix $s$. The formation of plural die into dice is by omitting $e$ and adding $c e$. As the rule shown, suffix $s$ is added to either noun or verb when it is ended with vowel and vowel $e$ (pies, ties, lies, vies) [4].

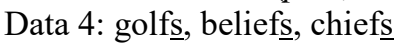

Golf, belief, and chief in plural form are showed by adding suffix $s$ but not suffix ves (golves, believes, and chieves). As the rule shown, the plural noun ended with consonant and consonant $f$ or vowel and consonant $f$ are formed by omitting $f$ and adding ves (thieves, leaves, wolves, elves) [8].

- Irregular plural noun formation

Data 1: books, boots, hooks, hoof $\underline{s}$

Book, boot, hook, and hoof in plural form are showed by adding suffix $s$ but not by changing double $o$ into double $e$ (beek, beet, heek, heef). As the rule shown, The double vowel $o$ in singular noun will be omitted and changed into double $e$ (teeth, feet, geese, ) [8].

Data 2: moose

Moose in plural form is showed by not changing the base word itself (moose). The plural form of moose does not add suffix $s$ or suffix es (mooses) or exchange double $o$ into double $e$ (meese).

Data 3: leeches, eels, bees

Leech, eel, and bee in plural form are showed by adding suffix $s$ or es. Nouns with double $e$ forms irregular without changing the base word (deer, sheep) [8].

Data 4: houses, blouses, spouses

House, blouse, and spouse in the plural form are showed by adding suffix s. Mouse and louse have the same pattern mo and use and lo and use which form mice and lice in plural form [4]. House, blouse, and 
spouse do not change the plural form such as hice, blice, spice.

Data 5: fruit

Flower, vegetable, and animal in plural form are showed by adding suffix s. Unlike fruit, the plural form of fruit does not put suffix $s$ [4].

Data 6: ethnics

There are ethnic and ethnics. Ethnics is a singular form [4] in sentences. In English, suffix $s$ or es put at the end of the noun shows plural form. Goodsis a plural noun, and it has no singular noun [8].

Data 7: shorts, pliers, scissors, spectacles

Those nouns are plural noun in a sentence. Physically, those nouns are one unit thing each and cannot be separated. They cannot be separated such as shoes and earrings.

Data 8: audience

Audience is a plural noun in sentences. This word is a collective noun so as it does not need suffix $s$ or es to show plural form. People and police are also collective nouns that do not need suffix $s$ or es, In fact, Audiences is used in the sentences to show the plural form, but by adding suffix $s$ to audience is incorrect.

Data 9: am not

There are constructions for helping verbs, verb be, and modal auxiliary andnot. There is not contraction for am and not

Data 10: shan't, won't

All constructions of helping verbs, verb be, and modal auxiliary and not are formed by suffixing $n$ ' $t$ after helping verbs, verb be, and modal auxiliary. This formation does not occur for shallnot and willnot (shalln't, willn't).The formation of shallnot and willnot by omitting double $l$ for shall and omitting double $l l$ and changing $i$ to $o$ for will.

- Verb Formation

Data 1: has

Have in singular form is showed by omitting ve and adding $s$. Mostly, suffix $s$ or $e s$ is added to a singular noun in a sentence. Leaves, lives, gives, and drives follow the rule in plural form.

Data 2: fly, flew, flown

The formation of fly to flew and flown is inconsistent. $C r y, f r y$, and $d r y$ are the verbs which have the same letter formation with fly. Cry, fry, and $d r y$ are formed by changing $y$ into $i$ and adding suffix $e d$ for the first and third verbs. Fly does not follow the rule (fly-fliedflied).

Data 3:need to

Need tohas the same lexical category with want to. Need todoes not have construction in informal conversation. Wanna and gonna are respectively informal words[4]. Those word are made of want to and going to. The word formation is shortened structurally by omitting the last two (want) and three letters (going) and the preposition to. And need todoes not have nenna.

- SuffixingFormation

Data 1: countryman, townsman

Countryman and townsman have different pattern from noun and zen (netizen, citizen, denizen). The nouns describe an inhabitant inhibiting in a particular place.

Data 2: fast, much, hard

Fast, much, and hard do not have form of adverb with suffix $l y$. Based on the rule, adverb of manner is formed by adding suffix $l y$ to the adjective such as happily, badly, and beautifully.

Data 3: good

The inconsistent formation of adverb is applied in good. Comparing to the word $\underline{\mathrm{bad}}$, the word bad forms badly for the adverb, but suffix ly cannot be applied in good (goodly). Instead, adverb of good is into well.

Data 4: shyly, dryly, slyly,

Particularly, in English word formation, the letter $y$ positioned at the end of the word is omitted and changed with the letter $i$. It happens to happily, sappily, daily, but it is not applied in shy (shily), dry (drily), sly (slily).

Data 5: anyway, anywhere, anything

Any added with another word as suffix will not change letter $y$ into $i$. As well as other words such as ladies, bunnies, flies, prettiest, they have letter $y$ at end, and the letter $y$ is omitted and changed with $i$.

Most European countries will add suffix $a$, an, ish to set the nationality such as German, Belgian, Croatian [8]. Another form is for the countries which have land ended. Usually the nationality is formed from suffix ish and the first syllable of the country name such as English, Polish, Irish [8]

Data 6:Swiss, Czech

There some nationality names deviate the rule. The Czech, Swiss do not add suffix an to form nationality as Swissan or Czechan.

Data 7:New Zealander, Icelander

The countries name above end with land but the name of nationality does not add suffix ish as New Zealish or Icelish.

Adjective can be formed another lexical category, noun, by adding suffix ness such as sadness, softness, and darkness [4].

Data 8: strength, length

The noun forming for the adjectives above is not added with suffix ness to the adjective. It is formed by omitting the letters from the vowel into ength. They do not follow the rule (strongness, longness).

Length is a noun, and long is an adjective. By adding suffix $y$ (lengthy), it forms an adjective. A noun added with suffix $y$ forms an adjective[4] such as healthy, wealthy, and creamy.

Data 9: strength 
Strength is a noun, and strong is an adjective. Unlike lengthy, strength cannot form adjective by adding suffix $y$ (strengthy)

Data 10: high-height, proud-pride

The noun formation of the adjective above does not follow the rule given neither adding suffix ness nor suffix ength.

Suffix en forms verbs from adjectives [8]. By adding suffix en, the adjective will form verb such as darken, soften, blacken, andlighten.

Data 11: strengthen, lengthen, heighten

The verbs are formed by adding suffix en to the noun but not to the adjective (strongten, longten, highten).

Data 12: proud

The adjective of proud has no verb. By knowing the pattern of verb making, proudcan be formed to be a verb by adding suffix en to proud (prouden) or adding suffix en to pride (priden). In fact, there is not the word prouden or priden.

Data 13: lessen

Less is the comparative form of little. Lessen is a verb of less. By adding suffix en to the word less, it forms a verb. There is no rule that suffix en will form verb for the second form of adjective.

Data 14: lesser

Less is a second adjective of comparison degree. It is the irregular adjective. But by adding suffix ertoless still has the same meaning with less and has the same lexical category with less (adjective). There is no rule that the second adjective of comparison degree can be added with suffix $e r$.

Data 15: minutely

The suffix $l y$ will form adjective for daily, weekly, yearly, andmonthly. These adjectives apply the meaning and function. Minutely is not part of those adjectives above in term of meaning and function. It is an adverb not an adjective. The meaning is not related to the time.

- Numeral Formation

Data 1: eleven, twelve, twenty, thirteen, thirty, fourteen, forty, fifteen, fifty

In case of number 1 and 2, their forms change completely at their teen numbers (not oneteen or twoteen). The formation number 5 to 15 and 50 , its two last letter ve changes to $f$ in teen number. And the formation number 3 to 13 and 30 has a minor change which omits double $\underline{e}$ to $\underline{i}$ before $\underline{r}$. Number 4 also has minor change by omitting $\underline{u}$ for forty.

Data 2: first, second, third,

Number 1, 2, and 3 form different ordinal number respectively. These formations happen for these three numbers. They are not added with suffix th as the rule given.

Data 3: fifth, ninth
These numbers follow the rule by adding suffix th. The formation number 5 to $5^{\text {th }}$ and $9^{\text {th }}$ is to omit $v e$ and change $\underline{v}$ to $f$, and number 9 omits $\underline{e}$.

Data 4: once, twice, thrice

These words have specific formation in showing the frequency number. The formation of these three numbers is by omitting the last vowels and adding the suffix ce and ice.

- Possession Formation

Data 1: myself, ourselves, yourself/selves, himself, herself, themselves, itself

The inconsistent formation of reflexive pronoun occurs because some reflexive pronouns add suffix self or selves to object pronoun (him, them) and possessive adjective ( $m y$, our).

Data 2: mine

Based on the rule, the formation of possessive pronoun is from possessive adjective and suffix $s$. But the possessive pronoun mine is not formed based on the rule (mys or mies)

\section{B. The Inconsistence of English Noun Phrase Formation}

Phrase is a group of word forming noun, adjective, and adverb in a sentence [8]. The formation of phrase also follows the rule that must be applied on phrase.

- Phrase made from noun and noun

Data 1: fingernail, football, classroom, paintbrush, textbook

The formation of compound noun is to combine the two nouns in a noun phrase. The first noun is a modifier to modify the second noun or head. The formation of compound noun is by separating the two nouns [8] such as sciencefiction, leathershoes, shophouse. Fingernail, football, classroom are noun formed by two different nouns. In fact, the formation of them is by combining the two nouns with no space.

Data 2: nostril

Nostril is the word formed by nose and hole. The word formed is not by combining the two words but it is formed with a new word. Earhole and pigeonhole are the noun phrases with adding hole.

- Present Participle Adjective Modifying Noun

Data 1: exit door, lose track, copy paper, sketch book, jump serve

Verb forms adjective to modify noun by adding suffix ing. The present participle will modify the noun when it is put in front of the noun such as washingmachine, swimmingpool, cyclingpath, joggingtrack, skippingrope. The formation of exitdoor, losetrack, copypaper, sketchbook, jump serve will not use present participle to modify the noun or head. The verbs retain its base form while modify the noun.

- Phrase Made from Noun and Adjective

Data 1: attorney general, secretary general, bishop elect, body politic. 
The phrase above is formed from noun and adjective. Based on the rule learned, noun does not modify the adjective

\section{The Inconsistence of English Sentence Formation}

- Modal Auxiliary

Data 1:had better not, would rather not

Not in negative form of the sentence with modal auxiliary hadbetter or wouldrather is positioned after better or rather (had better not). $\underline{\text { Not is not put after had }}$ or would. And there is no construction form of these words.

Data 2: Must .....?,

To form yes or no question, modal auxiliary must be positioned at the first of the question before subject. Must cannot form questions. It is replaced by have to with helping verb do or does.

Data 3: May you.......?

To form a yes or no question, maycannot be followed by you as a subject. Mostly may in a question form followed by $I$

Data 4: did not used to......,. Did you used to..?

Used tois a modal auxiliary. It can form positive, negative, and question form. As well, this modal auxiliary must follow rule grammatically. This form does not follow the rule. As the rule declares, the negative and the question forms with helping verb did will change the verb into the base form. In fact, there is did in negative and question form but the verb is still in the past form.

- The Formation of Question Tag

Data 1: I am ok, aren't I?

$I$ is a first singular person, the verb be of $I$ is $a m$ (present form). In this question tag, $I$ is followed by aren't. It is caused there is no contraction am not (amn't). Based the rule of grammar, $I$ cannot be matched with verb be are.

- The formation of If clause

Data 1: I were, she were, ...

The second type of if conditional expression, was is not allowed to be used regardless the subject singular noun for example If $I$ were a bird, I would fly.

Data 2: Had I gone to Jakarta, I would have bought you souvenir.

Based on the rule, the sentence started with verb be will form a question. In this case, the sentence formed with helping verb acts as a positive form in if conditional expression.

- The Use of Singular and Plural Verb in Sentences Formed by Either...or....

Data 1:

Either the child or the parents go to the school.

Either the parents or the child goes to school.

The sentences above show the different use of verb form although they use the same verbs go.

- The Use of Possessive Adjective in Sentences Formed by neither... nor
Data 1:Neither the teacher nor the students did their work.

The sentence above shows that the object pronoun represents one subject meanwhile there are two subjects. The object pronoun represents plural subject.

- The Use of verb be and an article in Collective Noun

Data 1:

The number of students is...,

A number of students are...

It is very different in this type of sentence. $A$ as an article in this collective noun acts as a plural by looking at the verb be are.

- The Use of The and Adjective

Data $1:$ The more.... The better....

There is an expression using the before adjective. The example expression is The earlier you come, the easier $u$ get the front chair. The rule made is that a single adjective cannot be attached with the.

- The Use of To and Present Participle

Data 1: look forward to seeing

The phrasal verb look forward is the verb followed by to and present participle. There is no any specific reason why it is followed by to and present participle

Data 2: I am used to eating

The phrasal verb used to followed by present verb be is followed by verb ing. There is no any specific reason why it is followed by to and participle

- The Question Formation

Based on the grammar rule, making question must add helping verb, verb be, or auxiliary in the beginning of yes or no question (Do you...?,Are u....?) or after whquestion (Where does...?, What are ...?, What time do...?). If there is no helping verb, the question can form a noun clause (I know what he did)

Data 1: Who goes ......? What happened....?

If the answer of the question is a subject either living thing or non-living thing, the simple present and past question will not put the helping verb $\underline{d o}$, does, $\underline{\text { did }}$ such as Who goes to school?, Who go to school?, Who went to school?, and what happened?

The area of the inconsistency of English words, phrases, and sentences finally occurred in the forms as follows below.

\section{A. The Inconsistenceof English Words Formation}

1) Regular and Irregular Plural Noun Formation

a) The use of suffix $s, e s$, en, ce, ves, to form plural noun

b) The formation of irregular plural noun without omitting double $o$ between consonants to double $e$

c) The formation of irregular plural noun by suffixing $s$ to the double $e$ between consonant

d) The formation of irregular plural noun by suffixings

e) The based word for singular and plural nouns

2) Verb Formation

a) The formation of singular verb has by omitting ve

b) The formation of irregular verb fly 
c) Need to with no construction

3) Suffixing formation

a) The inconsistent formation of adverb of manner without suffixing $l y$

b) The inconsistent formation of nationality address

c) The inconsistent formation of noun, verb, and adjective

4) Numeral Formation

a) The inconsistent formation of cardinal and ordinal number

5) Pronoun Formation

a) The inconsistent formation of possessive adjective and possessive pronoun

\section{B. The Inconsistence of English Noun Phrases Formation}

1) Phrase formed by noun and noun

a) The formation of noun phrase with and without separation

2) The formation of noun phrase with present participle and bare infinitive

3) The formation of noun phrase by combining noun and adjective

\section{The Inconsistence of English Sentences Formation}

1) The inconsistent formation modal auxiliary in negative and question forms

2) The inconsistent grammatical formation of the verb be are to the subject $I$ in tag question

3) The inconsistent grammatical formation of the verb be were to the singular subject in if clause

4) The inconsistent grammatical formation of front position of helping verb had as a positive form in if clause

5) The inconsistent use of singular and plural verb and possessive adjective in sentences formed by correlative conjunction either ,„,,or... and neither .......nor....

6) The inconsistent use of verb be and an article in sentences with collective noun.

7) The inconsistent formation of the and adjective and to and present participle

8) The inconsistent formation of question form.

D. The most inconsistent formation occurs in words in which suffixing formation experiences the inconsistent formation mostly.

E. The inconsistent formation of noun phrase occurs when the present participle or bare infinitive verbs modify noun

$F$. The inconsistent formation of sentences occurs mostly in the use of helping verb.

\section{CONCLUSION}

The mistakes of word, phrase, and sentence formation made by the EFL learners are because of morphosyntactical inconsistency of word, phrase, and sentence formation. The use of modal auxiliary may and must, regular plural noun formation, or the use of to and presentparticiple as a noun, verb, or adjective are the some of the mistakes made by the EFL learners. Result of the analysis given, there are a lot words, phrases, and sentences formation that do not follow the rule of English grammar taught in schools. The inconsistent formations of English words occur in regular plural noun formation, irregular plural noun formation, verb formation, suffixingformation, numeral formation, and possession formation. The inconsistent formations of English noun phrases occur in phrase made of noun and noun, present participle adjective modifying noun, and phrase made of noun and adjective. The inconsistent formations of English sentences occur in the formation of question tag, if conditional, and question, the use singular and plural verb in sentences formed by either...or...., modal auxiliary, object pronoun in sentences formed by neither... nor...., verb be and an article in collective noun, the and adjective, and to and present participle in the sentences. Most of the English learners applied the rules syntactically and morphologically without looking at whether the words, phrase, and sentences formationshave inconsistent formations.The interesting phenomena found in English grammar textbooks also do not explain the inconsistency of words, phrases, and sentences formation and English grammar textbooks do not explain why the formations of English words, phrases, and sentencesdo not follow the rulemorphologically and structurally.

\section{REFERENCES}

(1) Kieffer, M., \&Lesaux, N. Effects of academic language instruction on relation and syntactic aspects of morphological awareness for sixth grades from linguistically diverse background. The Elementary School Journal, 112(3), pp. 45-57. 2012. Retrieved at August 20, 2017 fromhttps://bit.ly/2NNSzK2

(2) Nagy, W., Berninger, V., \& Abbott, R.Contributions of morphology beyond phonology to literacy outcomes of upper elementary and middleschool students. Journal of Educational Psychology, 98(4), pp. 134-147. 2008. Retrieved at June $28^{\text {th }}, 2017$ from https://bit.ly/2wLVnzU

(3) Spuy, van der A. Construction morphology and inflection. Lingua, 199(2), pp. 60-71. 2017. Retrieved at June $3^{\text {rd }}, 2018$ from https://bit.ly/2Q5soQo

(4) Azar, B. S., \& Hagen, S. A. Basic English grammar (4th ed.). New York: Pearson Education Company. 2014.

(5) Hosseinzadeh, N. M. New blends in English language. International Journal of English Language and Linguistics Research, 2(2), pp. 15-26. 2014. Retrieved at June $10^{\text {th }}, 2017$ from https://bit.ly/2wJUWH6

(6) Finegan, E. Language; Its structure and use (7th ed.). Stamford: Cengage Learning. 2015.

(7) Florencia, S. Word formation process on Kaskus. LANTERN (Journal on English Language, Culture and Literature), 5(3), pp. 56-67. 2016. Retrieved at May 28 ${ }^{\text {th }}, 2018$ from https://bit.ly/2Q6kfvd

(8) Koneru, A. English language skills. New Delhi: Tata McGraw Hill Education Private Limited. (2011).

(9) Hickey, P. J. \& Lewis, T. The common core, English learners, and morphology 101: Unpacking LS.4 for ELLs. The Language and Literacy 
Spectrum, 23(1), pp. 69-84. 2012. Retrieved at June $10^{\text {th }}, 2018$ from https://bit.ly/2NjHX8O
(10) Sudaryanto. Metode dan aneka teknik analisis bahasa. Yogyakarta: Duta Wacana University Press. 2015. 